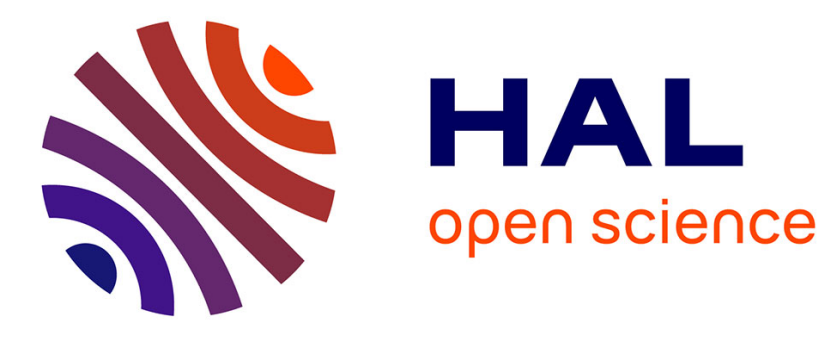

\title{
Linear induction actuators for a haptic interface: a quasi-perfect transparent mechanism
}

Alberto Cabezon Ortega, Antoine Weill-Duflos, Sinan Haliyo, Stephane Regnier, Vincent Hayward

\section{To cite this version:}

Alberto Cabezon Ortega, Antoine Weill-Duflos, Sinan Haliyo, Stephane Regnier, Vincent Hayward. Linear induction actuators for a haptic interface: a quasi-perfect transparent mechanism. 2017 IEEE World Haptics Conference (WHC), 2017, Munich, Germany. pp.529-534, 10.1109/WHC.2017.7989965 . hal-03190972

\section{HAL Id: hal-03190972 \\ https://hal.science/hal-03190972}

Submitted on 28 Apr 2021

HAL is a multi-disciplinary open access archive for the deposit and dissemination of scientific research documents, whether they are published or not. The documents may come from teaching and research institutions in France or abroad, or from public or private research centers.
L'archive ouverte pluridisciplinaire HAL, est destinée au dépôt et à la diffusion de documents scientifiques de niveau recherche, publiés ou non, émanant des établissements d'enseignement et de recherche français ou étrangers, des laboratoires publics ou privés. 


\title{
Linear Induction Actuators for a Haptic Interface: a quasi-perfect transparent mechanism
}

\author{
Alberto Ortega $^{1}$, Antoine Weill-Duflos ${ }^{1}$, Sinan Haliyo $^{1}$, Stéphane Régnier ${ }^{1}$ and Vincent Hayward ${ }^{2}$
}

\begin{abstract}
This article describes the design of a high-fidelity haptic interface based on a three-axis induction system. Unlike other type of actuators, linear induction motors can provide simultaneously a non-contact drive and a very low inertia. Their integration in a haptic device enables an interface with quasiperfect mechanical transparency. We detail the conception of linear induction motors for a haptic application and experimental results of a proof-of-concept interface driven by them are shown.
\end{abstract}

Index Terms-haptic device - haptic transparency - linear induction motor low inertia

\section{INTRODUCTION}

There exists no commercial haptic interface that achieves perfect structural transparency. Their mechanical structure comes with large handle inertia and/or limited dynamic range, resulting in a low level of transparency blurring and masking the perception of small or highly dynamic phenomena that are important to the human somatosensory system. Some of them achieve high degree of transparency with dedicated control scheme, but the usual conservative approach results in an ensured stability and a limited transparency [1], [2]. In other works high mechanical transparency has been achieved in single-axis interfaces using a dual-stage actuator technique [3].

In this paper we propose a three degree of freedom haptic device with a natural quasi-perfect transparent mechanism. The central technical objective is to eliminate any type of articulated joint in the structure, as well as the sources of friction and inertia. Note that Maglev technology has already been introduced to teleoperation systems with promising results in terms of transparency [4]. The preliminary concept calls for guiding very light and rigid moving part by an airbearing technique and to actuate it without contact through an innovative two-axis induction system based on linear induction actuators.

In Section II the concept of transparency is presented and related to the choice of linear induction motors as actuators for a haptic interface. Section III gives the fundamentals of linear induction motors and in Section IV the design criteria of the haptic interface are detailed. Section V describes the proof-of-concept assembly and in Section VI some experimental measurements are carried out. Section VII

\footnotetext{
1 A. Ortega, A. Weill-Duflos, S. Haliyo and S. Régnier are with Sorbonne Universités, UPMC Univ Paris 06, UMR 7222, ISIR, F-75005, Paris, France. \{ortega, weill, haliyo, regnier\}aisir.upmc.fr

2 Vincent Hayward is with the Centre for the Study of the Senses, School of Advanced Study, University of London, UK haywardeisir.upme. fr
}

presents concluding remarks and gives recommendations for the further development of the haptic device.

\section{ACTUATORS FOR A TRANSPARENT MECHANISM}

The main objective of a high fidelity interface is to provide a faithful transmission of signals to couple the operator as closely as possible to the remote environment. Ideally, the interface would be perfectly transparent and it would make the operators feel that they are interacting directly with the remote environment [1], [5]. The idealized teleoperation system with perfect transparency is usually designated as a massless, infinitely rigid stick [6].

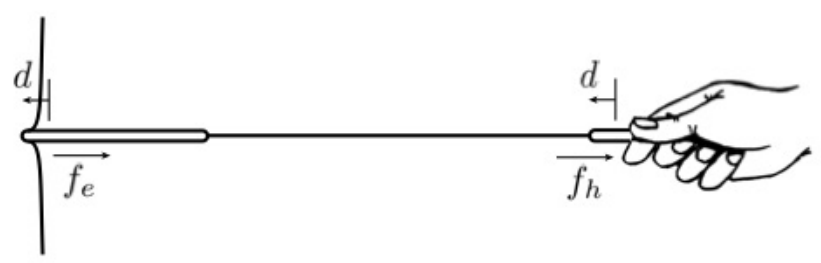

Fig. 1. Idealized teleoperator [7]

In a haptic interface, high transparency depends on reducing the parasitic forces under the smallest human detectable force under all desired operating conditions [8]. The magnitude of these parasitic forces owes mainly to friction and inertia. An interface with no mechanical joints and with a very low inertia would reduce these parasitic forces to a minimum and thus present a structure with a high degree of mechanical transparency. Based on that, the use of electromagnetic machines and non contact forces in a haptic device would increase the fidelity of the manipulation.

Different kind of electromagnetic machines allow a noncontact transmission of forces. Since a two-axis system of actuation is desired, the analyze will be constrained to linear electromagnetic machines. These latter can be classified into four categories: Linear Synchronous Motors (LSM), Linear Direct-current Motors (LDM), Linear Pulse Motors (LPM) and Linear Induction Motors (LIM). To allow unrestricted free exploration, the inertia of the device should be kept to a minimum [9]. The category with the lightest secondary or moving part and consequently the lowest inertia is the linear induction motor, which can have different topologies. The best solution to avoid the steel in the secondary that would increase the inertia is the double-sided topology instead of the single-sided. Thus double-sided linear induction motors (DLIM) were considered as very well suited actuators to achieve high mechanical transparent devices. 


\section{LINEAR INDUCTION MOTORS' THEORY}

Based on the theory of linear induction motors [10], some important parameters have to be considered during their design. One of them is the goodness factor G. This metric, developed by Eric Laithwaite, is related to the motor performance and it enables the efficient development of a DLIM [11].

$$
G=\frac{2 \cdot \mu_{0} \cdot f \cdot \tau^{2}}{\pi \cdot \rho_{s} \cdot g}
$$

where $\mu_{0}=4 \pi \cdot 10^{-7} \mathrm{H} / \mathrm{m}$ is the permeability of the air, $f$ is the source frequency in $\mathrm{Hz}, \tau$ is the pole pitch of the primary winding in $\mathrm{m}$ as illustrated in Fig 3, $\rho_{s}$ is the surface resistivity of the secondary conducting sheet in $\Omega / \mathrm{m}^{2}, g$ is the airgap in $\mathrm{m}$. This is an idealized metric that do not take into account certain phenomena inherent to the linear induction motors' nature, such as the airgap leakage, the secondarysheet skin effect, and transverse edge effects [12].

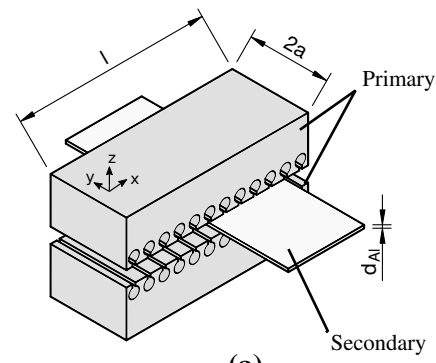

(a)

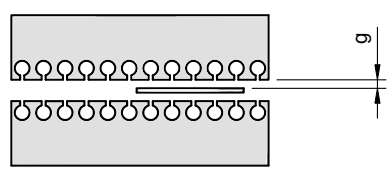

(b)
Fig. 2. DLIM isometric (a) and lateral (b) drawing with the main geometrical parameters

Another important parameter for the DLIM design is its thrust $F_{x}$, with the reference of Fig 2 . This latter is given by the following equation [10]:

$$
F_{x}=\frac{3 \cdot \pi \cdot L_{m} \cdot I_{1}^{2} \cdot s \cdot G_{e}}{\tau \cdot\left(1+s^{2} \cdot G_{e}^{2}\right)}
$$

where $I_{1}$ is the rms value of primary phase current in A, $s$ is the slip, $G_{e}=G / k_{1}$ where $k_{1}$ is a coefficient that takes into account edge effect, Joule effect, skin effect, airgap fringing and stator slotting. $L_{m}$ is the magnetization inductance in $\mathrm{H}$ and it is given by [10]

$$
L_{m}\left(w_{1}\right)=\frac{6 \cdot \mu_{0} \cdot\left(2 a_{e}\right) \cdot\left(k_{w 1} \cdot W_{1}\right)^{2} \cdot \tau}{\pi^{2} \cdot p \cdot g_{e_{A l}} \cdot\left(1+k_{s s}\right)}
$$

where $w_{1}$ is the primary angular frequency (in $\mathrm{rad} / \mathrm{s}$ ), $k_{w 1}$ is the winding factor, $W_{1}$ is the turns in series per phase, $d_{A l}$ is the secondary sheet thickness in $\mathrm{m}, p$ is the number of pair of pols, $a_{e}=a+\frac{g_{e} A l}{2}$ in $\mathrm{m}$ with $2 a$ the stack width in $\mathrm{m}$, $g_{e_{A l}}=\left(2 \cdot g+d_{A l}\right)^{2} \cdot k_{2}$ in $\mathrm{m}$ where $k_{2}$ is a coefficient that takes into account the slot opening and the airgap fringing, $k_{s s}$ is a coefficient that takes into account the stator magnetic saturation. As seen in equation 2 , small variations in $I_{1}$ induce great variations in the thrust.

\section{DESIGN OF LINEAR INDUCTION MOTORS FOR A HAPTIC INTERFACE}

\section{A. Performance criteria}

Inspired by commercial touch-pads but aiming for smaller sizes in this first prototype, the workspace was define as a $50 \times 50 \mathrm{~mm}$ square. Target values specifying the characteristics of a haptic interface that can operate at the limits of human performance have already been suggested [3]. Based on that, the moving part of the interface was limited to $50 \mathrm{~g}$. Considering the smooth manipulation of the interface, where the user would drive the moving part with one up to three fingers, the maximum force was set to $2 \mathrm{~N}$. As a first approach, a single DLIM's dynamic was estimated to cover all the human motor capabilities and no time-domain performances such as rise time were taken into account during the design [13].

\section{B. Design approach}

As a first approximation most of the side effects were ignored and the coefficients were define as: $k_{w 1}=k_{1}=$ 1 and $k_{s s}=0$. Considering the wished low inertia of the interface, the secondary's thickness was defines as $d_{A l}=$ $0.5 \mathrm{~mm}$.

The proof-of-concept interface design is shown in Fig 8. With this disposition of the DLIMs, a working space of $50 \times 50 \mathrm{~mm}$ and a vacuum preloaded air bearing with a $50 \mathrm{~mm}$ diameter (see discussion in section V), the length of the DLIMs was set to $l=125 \mathrm{~mm}$. As seen in (3) and (2) the wider the DLIM is, the higher the generated thrust is. On the other side and as it can be seen in 8, the wider the DLIM, the longer the secondary and thus the higher the inertia of the interface. Taking all that into account, an intermediate value of $2 a=30 \mathrm{~mm}$ was arbitrarily defined. The lower the air gap, the higher the thrust is. Nevertheless their is a mechanical limit of this air gap imposed by the disposition of Fig 8, that shows that the DLIM's secondary will mechanically behave as a cantilever. To absorb the secondary's deflection and thus avoid any kind of friction between secondary and primary in the DLIMs, an air gap of $g=2 \mathrm{~mm}$ was determined.

Regarding the haptic performance of the interface, a thrust of $2 \mathrm{~N}$ per motor was considered enough. With an oversizing design strategy in this first prototype, the maximum thrust was defined as $F_{x}=6 \mathrm{~N}$ and $I_{1}=2 \mathrm{~A}$ the current to reach this thrust. To reduce the harmonics on the air gap, a double-layer winding with half-filled end slots was adopted [14]. Thus with the winding shown in Fig 3 and a 3-phase system, 12 was an appropriate number of slots per motor, which result in a number of poles $2 p=4$.

$$
\tau=\frac{l}{2 p}
$$

which gives $\tau \approx 31 \mathrm{~mm}$. With all these numbers in (3):

$$
L_{m}\left(W_{1}\right) \approx 1.22 \cdot 10^{-7} \cdot W_{1}^{2}
$$

The optimum goodness criterion [12] suggested $G e=10$ for $2 p=4$. Expecting a low slip $s=0.1$, (2) gave:

$$
F_{x}=6 \approx 7.36 \cdot 10^{-5} \cdot W_{1}^{2}
$$


and finally $W_{1} \approx 285$.

Since there are 3 coils in series per phase, the number of turns per coil is given by

$$
N_{\text {coil }}=\frac{W_{1}}{3}
$$

After all these approximative design, it arised $N_{\text {coil }}=95$ rounded to 100 turns/coil.

\section{Primary: electrical steel core with built-in winding}

The raw material used for each linear induction motor are prisms of $30 \times 30 \times 120 \mathrm{~mm}^{3}$ made of insulated sheets of M530-50A steel. This latter corresponds to electrical steel non grain oriented and presents a high relative permeability. To mechanize the slots and keep the laminated steel assembled, a machining process with low efforts was required. The solution adopted was the wire electrical discharge machining.

Once the core of the linear induction motor was mechanized, the coils were built-in. With 9 individual coils, 3 per phase, the assembly was disposed following Fig 3. Finally the core with built-in coils was covered with resin, having just access to both extremities of each phase.

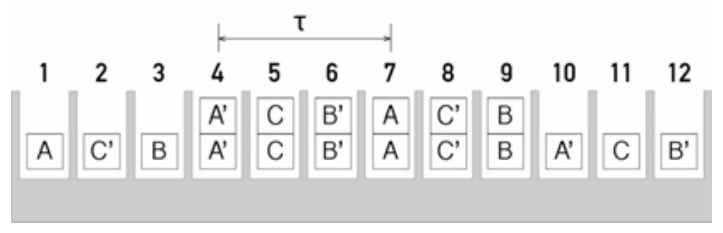

Fig. 3. Double-layer winding disposition.

\section{Secondary: the moving part}

The secondary has to be a paramagnetic and electrical conductive material, and the higher the electrical conductivity is, the higher the thrust induced on the secondary is [15]. As one of the main technical objectives is to design a low inertia moving part in the haptic device, materials with a low density were prioritized. In this case the material with the best weight/conductivity ratio was the aluminum. Regarding geometrical parameters, the secondary had to be thin enough to permit a small airgap in the DLIM as well as a low amount of parasite currents. Its width should permit a good dissipation of the warmth and a good thrust, being the pole pitch of the primary winding $\tau$ a lower limit for it. Experimentally we realized that a wider secondary would reduce the vibrations felt while manipulating the interface. With all this considerations the secondary of the DLIM resulted in a $0.5 \mathrm{~mm}$ thick and $5 \mathrm{~mm}$ wide sheet of 1050 aluminum alloy.

\section{CONTACT Free-HAPtic InTERface}

As already mentioned, one of the central objective with this haptic interface is to eliminate any type of articulated joint in the structure. This is reached with a two-axis motor system based on linear induction motors, whose layout is shown in the Fig 4. Considering that each DLIM induces a unique longitudinal force, at least 3 of them are required to cover a two-dimension working space. With this system, $\mathrm{X}$ and $\mathrm{Y}$ forces as well as a torque in the Z-direction can be induced over a moving aluminum plate. This interface claims to eliminate the sources of inertia and friction and the different parts of the interface are conceived to reduce them as much as possible.

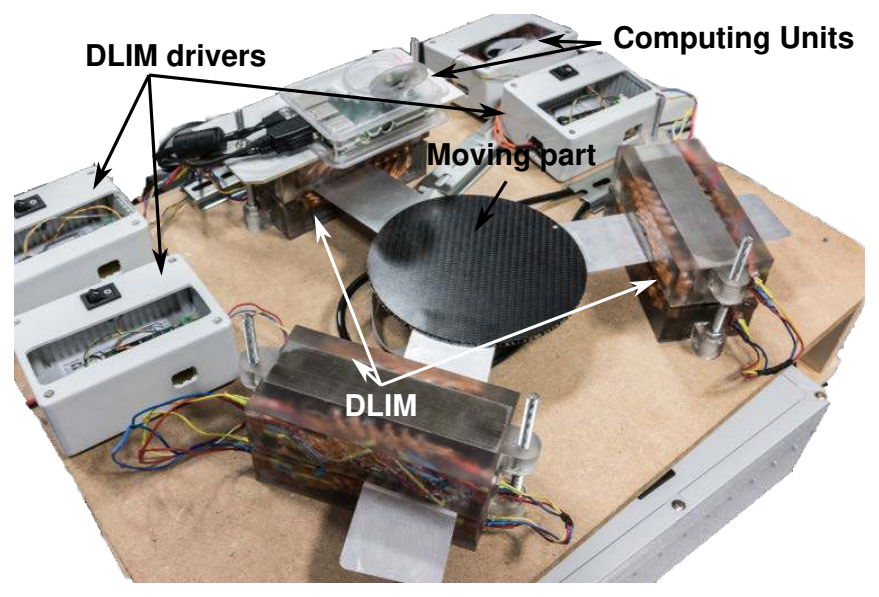

Fig. 4. Haptic interface with an actuation based on linear induction motors.

\section{A. Moving plate and air-bearing}

In a haptic interface, friction and inertia are the main sources of parasitic forces that distort the perception of physical phenomena. The induction system based on three DLIMs eliminates all the friction related to the drive, but there is still the friction related to the displacement of the moving part. To reduce it, an air-bearing technique was adopted. The idea is to manipulate the moving plate of the interface over a thin film of pressurized air, the same way the puck on an air hockey table is floating on air.

Gas film bearings allow a clean working conditions and they operate with zero static and dynamic friction where liquid fluid film bearings have much higher friction and pumping losses. To maintain a constant air gap and maximize the stiffness of the air bearing, a preload is required. The preferred solution was vacuum preloaded, since it helps to maintain constant air gap without adding unnecessary moving mass, which is essential for the low inertia objective of the moving plate. Thus, a small commercial vacuum preloaded air bearing (model S205001; New Way Air Bearings) was integrated in the interface.

Another central objective was to achieve a very low handle inertia, a property that has been demonstrated to be fundamentally important for optimal coupling with the operator [16], [8]. Considering the actuators characteristics, a $0.5 \mathrm{~mm}$ thick and $5 \mathrm{~mm}$ wide sheet of 1050 aluminum alloy was chosen as secondary for the DLIMs. Nevertheless, the vacuum preload induces bending stresses that would deform the aluminum. A structure offering excellent rigidity and minimal weight is the carbone fiber with aramid honeycomb core. This composite material was then used as the "puck" 
floating on the air bearing, and on it three $0.5 \mathrm{~mm}$ thick and $5 \mathrm{~mm}$ wide sheets of 1050 aluminum alloy would be stuck, each one corresponding to the secondary of each linear induction motor.

\section{B. Impedance control}

Bi-directional information flow is the most distinguishing feature of haptic interfaces. To control them, there are two main types of strategies: the impedance-control and the admittance-control. The impedance-control is the most common and it is the one adopted for the prototype here presented. With this approach, the virtual environment defined specifies the forces that have to be generated by the device's actuators in response to moving the device: a force is send and a displacement is measured [7]. Compared to the admittance-control it has a cheaper and easier implementation. A force control is also more interesting for the rendering of virtual textures, but it requires a device that reacts with large changes in forces to small changes in the position [17]. Thus, a precise measurement of the displacement is required, as well as a characterization of the electrical impedance of the system to design the appropriate electronic.

1) Position sensing: The impedance-control requires the position sensing of the moving part. To preserve the mechanical transparency of the interface, a non contact method was preferred. Taking into account other parameters such as resolution, sensing speed and the kind of displacements to measure, the laser sensing was adopted. To measure the $\mathrm{X}$ and $\mathrm{Y}$ displacements as well as the Z-rotations over all the working space of the device, three laser motion sensor (model ADNS-9800; Avago) were arranged in the interface. To read the signals of the three sensors, a usb/based microcontroller (teensy 3.2; PJRC) was used. Each sensor has a frame rate up to $12,000 \mathrm{fps}$ and even if the reading of the data of the three laser sensors was slower, update rates over the $1 \mathrm{kHz}$ required by the sense of touch were achieved.[18].

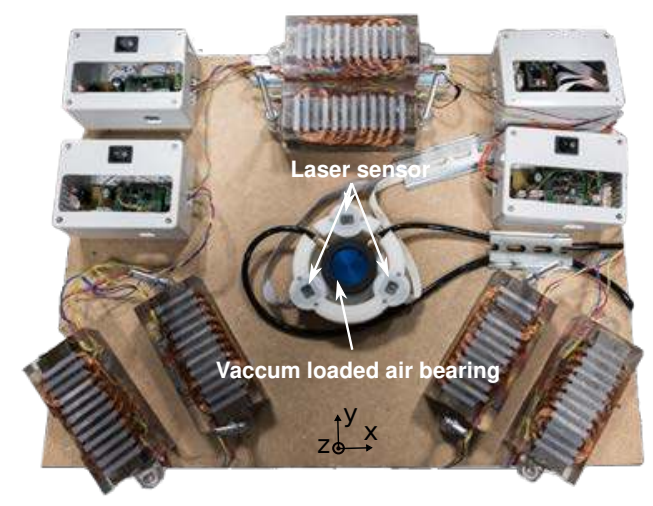

Fig. 5. Air bearing and position sensor system.

2) Electrical impedance of the linear induction motor: To create a moving magnetic field with the three-phase winding disposition of the laminated steel core, it was necessary to supply a three-phase signal. The most appropriate was a three-phase balanced sinusoidal signal. To find the electronic capable of doing that, the impedance value of the coils had to be calculated. Thee theoretical equations of a coil resistance $R_{\text {coil }}$ and impedance $L_{\text {coil }}$ are:

$$
R_{\text {coil }}=\rho_{C u} \frac{l_{C u}}{S}
$$

where $\rho_{C u}=1,68 \cdot 10^{-8} \Omega / \mathrm{m}$ is the resistivity of the copper, $l_{C u}$ is the length of the copper wire in $\mathrm{m}$ and $S$ is the crosssectional area of the copper wire in $\mathrm{m}^{2}$

$$
L_{\text {coil }}=\frac{\mu_{0} \mu_{r} N_{c o i l}^{2} S}{l_{C u}}
$$

where $\mu_{r}$ is the relative magnetic permeability of the material of the linear induction motor. This value varies with the magnetic field and at 0,002 Tesla for electrical steel $\mu_{r_{\text {ElSteel }}}=$ 4000. This value will be taken for a first calculation.

The design of the single-sided motor was done considering a maximum current of $2 \mathrm{~A}$ per phase, which following the tables of $\mathrm{AWG}$ wire sizes requires a wire with a diameter of $0,4 \mathrm{~mm}$. With such a wire and with the geometry of the prototype, a coil of $l_{C u} \approx=14400 \mathrm{~mm}$ and $S \approx 0.823 \mathrm{~mm}^{2}$, will have a resistance of $R_{\text {coil }} \approx 2.9 \Omega$ and an inductance $L_{\text {coil }} \approx 4.1 \cdot 10^{-5}$ according to (4) and (5).

The theoretical impedance of a coil is

$$
Z_{\text {phase }}^{2}=R_{\text {phase }}^{2}+\left(w L_{\text {phase }}\right)^{2}
$$

where $Z_{\text {phase }}$ is the impedance of one phase, $R_{\text {phase }}$ is the resistance of one phase, $w$ is the angular frequency of the phase's signal and, $L_{\text {phase }}$ is the inductance of one phase.

With the equation (6) the impedance of a phase of the linear induction motor can be deduced. There are three coils per phase, and depending wether they are connected in series or in parallel, it results:

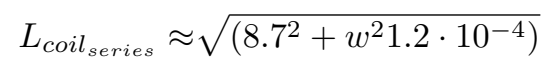

and

$$
L_{\text {coil }}^{\text {parallel }} \approx \sqrt{\left(0,97^{2}+w^{2} 5.6 \cdot 10^{-10}\right)}
$$

As it will be explained later, the operational frequency of the induction motors had to be over $600 \mathrm{~Hz}$ for a good haptic sensation. A series connexion of the coils and an operational frequency over $600 \mathrm{~Hz}$ would demand too high voltages. That is why the coils were finally connected in parallel.

3) DLIMs drivers: To drive the linear induction motors, three commercial 4-quadrant PWM servo controller for brushless EC motors were used (model ESCON Module 50/5; Maxon Motor). These controllers are optimized for driving permanent-magnet brushless electric motors. In the case of a three-phase permanent magnet motor, the structure of the driver is typically a 3-leg 6-switch bridge inverter that can also be used to drive a 3 phase induction motor as well.

These controllers can deliver $5 \mathrm{~A}$ per phase at $50 \mathrm{~V}$ and in order to operate they need the hall-effect sensor which within the standard EC motors it is usually provided. In this case, the signal sets the working frequency of the linear induction motor and to recreate it artificially a teensy microcontroller was employed. The operating mode set was 
current control, where the actual motor current is compared with the applied set value. In case of deviation, the motor current is dynamically readjusted.

A single-board computer (model Raspberry PI 3) was used as central master: it collects the data from the teensy that reads the laser sensors, and with this information it sets the hall sensors signals of each motor. For that, the raspberry Pi 3 runs a program that takes into account the disposition of the linear induction motors and the virtual environment.

\section{EXPERIMENTAL MEASUREMENTS}

The interface presented a moving plate of $55 \mathrm{~g}$ and the feeling of inertia was very low while manipulating it over the airbearing. For this latter the air compressor supply of the laboratory was used.

Working at $50 \mathrm{~Hz}$ translated into a very uncomfortable manipulation of the interface. Indeed, the aluminum would then vibrate at $300 \mathrm{~Hz}$ and provoked unpleasant sensations. The vibration would transmit to the manipulandum and obviously deteriorate the haptic feedback acting as a mechanical noise. As the vibration is equal to 6 times the working frequency of the device, the solution to remove it was to work at higher frequencies. This would consequently increase the electrical impedance of the coils. To keep reasonable operational voltages, each phase coils connection was modified from a series connection of the original design to a parallel connection. Experimentally the working frequency was set to $660 \mathrm{~Hz}$, which made the aluminum plates resonate at $3960 \mathrm{~Hz}$ and provided a more comfortable manipulation.

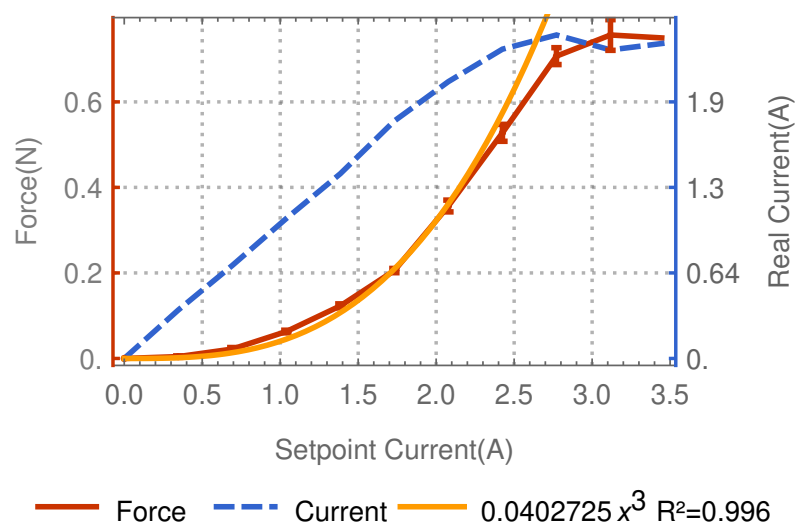

Fig. 6. Relation between the thrust of a linear induction motor (Force), the setpoint of current and the real output current of the electronic driver (Motor current)

For the measurements a force sensor was mounted on one of the aluminum plates and a digital scope recorded simultaneously the closed loop current of the electronic drivers and the force sensor signal. A thrust-intensity empirical relation is shown in Fig 6. Each point corresponds to the mean of ten measurements and their standard deviation is included in Fig 6. Detailed measurement values with percent relative standard deviations can be found in table I. Around $2.2 \mathrm{~A}$ the electronic driver starts to limit its output current and then
Values

TABLE I

VALUES AND RELATIVE STANDARD DEVIATIONS OF FIG 6

\begin{tabular}{|c|c||c|c|}
\hline Current(A) & RSD of Current (\%) & Force (N) & RSD of Force (\%) \\
\hline \hline 0 & 0 & 0 & 0 \\
\hline 0.355 & 1.16 & 0.00413 & 42.95 \\
\hline 0.704 & 0.75 & 0.0205 & 19.16 \\
\hline 1.054 & 0.44 & 0.0539 & 4.28 \\
\hline 1.411 & 0.53 & 0.105 & 4.36 \\
\hline 1.772 & 0.34 & 0.18 & 2.15 \\
\hline 2.129 & 0.51 & 0.323 & 3.80 \\
\hline 2.347 & 0.42 & 0.51 & 3.51 \\
\hline 2.355 & 0.25 & 0.642 & 2.88 \\
\hline 2.338 & 0.58 & 0.649 & 5.02 \\
\hline 2.348 & 0.31 & 0.638 & 2.06 \\
\hline
\end{tabular}

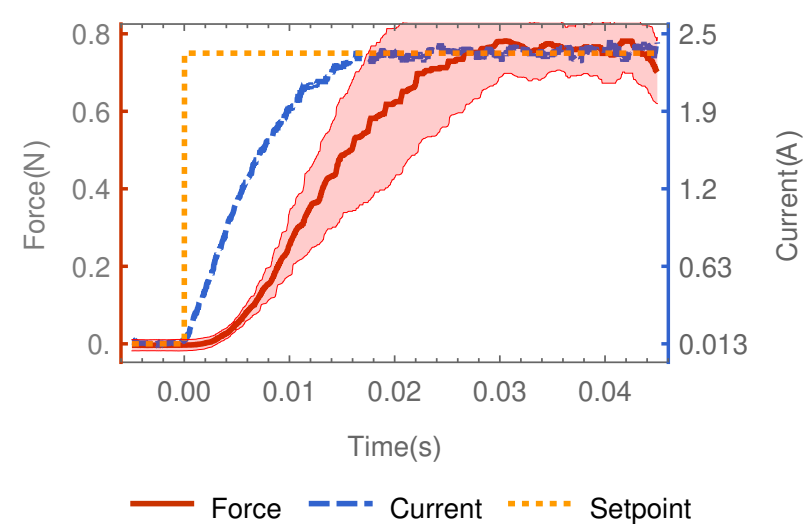

Fig. 7. DLIM response to a step

reaches a maximum value. The thrust increases despite the driver's saturation: this may be explained by the capacity of the amplifier to overcome this limit for a short amount of time. Below 2.2 A, the thrust-current quadratic relation expected from (2) appears empirically as a cubical function. This can be due to the electronic drivers solution adopted for this proof of concept.

TABLE II

SAMPle of VAlues and Relative STANDARd DEVIATIONS OF Fig 7

\begin{tabular}{|c||c|c||c|c|}
\hline Time (s) & Current (A) & RSD (\%) & Force (N) & RSD (\%) \\
\hline \hline 0.01 & 1.89 & 0.621 & 0.256 & 9.42 \\
\hline 0.015 & 2.25 & 0.695 & 0.486 & 10.5 \\
\hline 0.02 & 2.33 & 0.97 & 0.623 & 10.4 \\
\hline 0.025 & 2.35 & 0.733 & 0.717 & 6.68 \\
\hline 0.03 & 2.32 & 0.867 & 0.78 & 3.92 \\
\hline 0.035 & 2.32 & 0.59 & 0.771 & 2.89 \\
\hline 0.04 & 2.35 & 0.622 & 0.75 & 3.41 \\
\hline
\end{tabular}

The time constant of the interface was also measured empirically in Fig 7. Three different values are displayed: the force measured by the force sensor, the closed-loop current of the electronic drivers and the step signal (setpoint) sent to the device. An average of eighteen measurements is used and the standard deviation of the force is shown. The table II offers some numerical sample at cue points. The current presents 
a response time of $15 \mathrm{~ms}$ at $5 \%$. Concerning the measured forces, the mean time constant is $25 \mathrm{~ms}$ ranging from $17 \mathrm{~ms}$ to approximately $30 \mathrm{~ms}$.

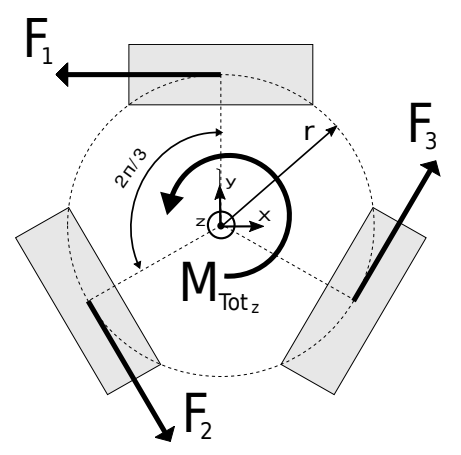

Fig. 8. DLIMs disposition and generated forces on the moving part

All the measurement where made on a single motor. Considering the disposition of the motors, this results can be applied to the interface. As shown in Fig 8, the motors are tangential to a circle of radius $r$ and at 60 degrees one from each other. Based on the reference of Fig 8, the relation linking the interface forces and the ones delivered by the DLIMs are, :

$$
\begin{aligned}
F_{\text {Tot }_{x}} & =-F_{1}+\frac{F_{2}}{2}+\frac{F_{3}}{2} \\
F_{\text {Tot }_{y}} & =-\frac{\sqrt{3} F_{2}}{2}+\frac{\sqrt{3} F_{3}}{2} \\
M_{\text {Tot }_{z}} & =r \sum_{i=1}^{3} F_{i}+x \frac{\sqrt{3}}{2}\left(F_{2}-F_{3}\right)+y\left(\frac{F_{2}+F_{3}}{2}-F_{1}\right)
\end{aligned}
$$

with $F_{i}$ the forces of the 3 DLIMs (the force is positive if it creates a positive torque), $(x, y)$ the position of the center of the moving plate, $F_{\text {tot }_{x}}$ and $F_{\text {tot }_{y}}$ the total force of the interface in the $\mathrm{x}$ and $\mathrm{y}$-axis respectively induced in the moving plate and $M_{t o t_{z}}$ the torque on the center of the moving plate in the $\mathrm{z}$-axis.

\section{CONCLUSION AND DISCUSSION}

We describe a haptic interface that works with a quasiperfect structural transparency. Indeed, the drive system based on linear induction motors and the air-bearing system eliminate any parasitic forces due to friction, leaving the very low inertia of the moving part as the last barrier to a perfect structural transparency. Experimental tests have shown an extremely smooth and comfortable haptic feeling of manipulation, but more control has to be implemented to reproduce virtual environments with high fidelity.

Not only control improvements but also design ones have to be pointed. Mutual inductances, non symmetrical disposition of the coils and Joule and end effects among others contribute to a non uniform thrust over the aluminum plate all along the DLIM. Different parameters could be tuned to achieve higher performances, such as the winding configuration to limit the end-effect or the number of phases to reduce the feeling of creeks while working at low frequencies.

Linear induction motors are usually present in transportation and the theory related to them has been developed based on that. Their characteristics make them very well suited for haptic applications and further work should involve analytical study of this topic. Perceptual vibrations, compactness and thrust could be the basis of this new generation of haptic actuators.

\section{ACKNOWLEDGMENTS}

The authors would like to thanks specially Bernard Javot for his manufacturing assistance and Thomas Daunizeau for his engineering advice.

\section{REFERENCES}

[1] D. A. Lawrence, "Stability and transparency in bilateral teleoperation," IEEE transactions on robotics and automation, vol. 9, no. 5, pp. 624637, 1993.

[2] A. M. Ousaid, A. Bolopion, S. Haliyo, S. Régnier, and V. Hayward, "Stability and transparency analysis of a teleoperation chain for microscale interaction," in 2014 IEEE International Conference on Robotics and Automation (ICRA), pp. 5946-5951, IEEE, 2014.

[3] G. Millet, S. Haliyo, S. Régnier, and V. Hayward, "The ultimate haptic device: First step," in EuroHaptics conference, 2009 and Symposium on Haptic Interfaces for Virtual Environment and Teleoperator Systems. World Haptics 2009. Third Joint, pp. 273-278, IEEE, 2009.

[4] S. E. Salcudean, N. Wong, and R. L. Hollis, "A force-reflecting teleoperation system with magnetically levitated master and wrist," in Robotics and Automation, 1992. Proceedings., 1992 IEEE International Conference on, pp. 1420-1426, IEEE, 1992.

[5] S. Hirche, A. Bauer, and M. Buss, "Transparency of haptic telepresence systems with constant time delay," in Proceedings of 2005 IEEE Conference on Control Applications, 2005. CCA 2005., pp. 328-333, IEEE, 2005.

[6] D. A. Lawrence and J. D. Chapel, "Performance trade-offs for hand controller design," in Robotics and Automation, 1994. Proceedings., 1994 IEEE International Conference on, pp. 3211-3216, IEEE, 1994.

[7] V. Hayward and K. E. MacLean, "Do it yourself haptics: part i," IEEE Robotics \& Automation Magazine, vol. 14, no. 4, pp. 88-104, 2007.

[8] A. Mohand-Ousaid, G. Millet, S. Régnier, S. Haliyo, and V. Hayward, "Haptic interface transparency achieved through viscous coupling," The International Journal of Robotics Research, vol. 31, pp. 319-329, Mar. 2012.

[9] V. Hayward and O. R. Astley, "Performance measures for haptic interfaces," in Robotics research, pp. 195-206, Springer, 1996.

[10] I. Boldea, Linear electric machines, drives, and MAGLEVs handbook. CRC Press, 2013.

[11] E. Laithwaite, "The goodness of a machine," Electrical Engineers, Proceedings of the Institution of, vol. 112, no. 3, pp. 538-541, 1965.

[12] I. Boldea and S. Nasar, "Optimum goodness criterion for linearinduction-motor design," Electrical Engineers, Proceedings of the Institution of, vol. 123, no. 1, pp. 89-92, 1976.

[13] E. Samur, Performance metrics for haptic interfaces. Springer Science \& Business Media, 2012.

[14] S. Yamamura, "Theory of linear induction motors," New York, Halsted Press, 1979. 246 p., 1979.

[15] H. Noma, S. Yoshida, Y. Yanagida, and N. Tetsutani, "The proactive desk: A new haptic display system for a digital desk using a 2dof linear induction motor," Presence: Teleoperators and Virtual Environments, vol. 13, no. 2, pp. 146-163, 2004.

[16] A. Mohand Ousaid, G. Millet, S. Haliyo, S. Régnier, and V. Hayward, "Feeling What An Insect Feels," PloS ONE, vol. 9, no. 10, p. e108895, 2014.

[17] M. A. Otaduy and M. C. Lin, "High fidelity haptic rendering," Synthesis Lectures on Computer Graphics and Animation, vol. 1, no. 1, pp. 1-112, 2006.

[18] V. Hayward, O. R. Astley, M. Cruz-Hernandez, D. Grant, and G. Robles-De-La-Torre, "Haptic interfaces and devices," Sensor Review, vol. 24, no. 1, pp. 16-29, 2004. 